Article

\title{
Sensitive Electrochemical Detection of Tryptophan Using a Hemin/G-Quadruplex Aptasensor
}

\author{
Ayemeh Bagheri Hashkavayi ${ }^{1}$, Jahan Bakhsh Raoof ${ }^{2} \mathbb{D}$ and Ki Soo Park ${ }^{1, * \mathbb{C}}$ \\ 1 Department of Biological Engineering, College of Engineering, Konkuk University, Seoul 05029, Korea; \\ elnazbagheri@konkuk.ac.kr \\ 2 Electroanalytical Chemistry Research Laboratory, Department of Analytical Chemistry, Faculty of Chemistry, \\ University of Mazandaran, Babolsar 47416-95447, Iran; j.raoof@umz.ac.ir \\ * Correspondence: akdong486@konkuk.ac.kr
}

Received: 13 September 2020; Accepted: 12 October 2020; Published: 15 October 2020

\begin{abstract}
In this study, we design an electrochemical aptasensor with an enzyme-free amplification method to detect tryptophan (Trp). For the amplified electrochemical signal, the screen-printed electrode was modified with dendritic gold nanostructures (DGNs)/magnetic double-charged diazoniabicyclo [2.2.2] octane dichloride silica hybrid $\left(\mathrm{Fe}_{3} \mathrm{O}_{4} @ \mathrm{SiO}_{2} / \mathrm{DABCO}\right)$ to increase the surface area as well as electrical conductivity, and the hemin/G-quadruplex aptamer was immobilized. The presence of Trp improved the catalytic characteristic of hemin/G-quadruplex structure, which resulted in the efficient catalysis of the $\mathrm{H}_{2} \mathrm{O}_{2}$ reduction. As the concentration of $\operatorname{Trp}$ increased, the intensity of $\mathrm{H}_{2} \mathrm{O}_{2}$ reduction signal increased, and Trp was measured in the range of $0.007-200 \mathrm{nM}$ with a detection limit of $0.002 \mathrm{nM}$. Compared with previous models, our sensor displayed higher detection sensitivity and specificity for Trp. Furthermore, we demonstrated that the proposed aptasensor successfully determined Trp in human serum samples, thereby proving its practical applicability.
\end{abstract}

Keywords: magnetic nanocomposite; aptamer; tryptophan; G-quadruplex; electrochemical sensor; dendritic gold nanostructures

\section{Introduction}

Tryptophan (Trp), an essential amino acid for humans, serves as a precursor for some biological molecules and structural component in proteins [1,2]. So far, different methods have been reported for measuring Trp, such as high-performance liquid chromatography (HPLC) [3], spectroscopy [4,5], and chemiluminescence [6]. As alternatives, many innovative approaches have been developed. For example, Eser et al. used ultra-HPLC coupled to electrospray ionization triple-quadrupole mass spectrometry to detect $\operatorname{Trp}$ [7]. In another study, Hazra et al. used resonance energy transfer between $\mathrm{Ce}^{3+}$ and $\mathrm{Tb}^{3+}$ ions in $\mathrm{Ce}^{3+} / \mathrm{Tb}^{3+}$-doped $\mathrm{CaMoO}_{4}$ nanocrystals to detect $\operatorname{Trp}$ [8]. However, these methods have the limitations such as complicated sample preparation, long periods of time to acquire measurements, and the need for advanced and costly laboratory tools. Therefore, electrochemical methods are highly regarded as the simple and low-cost alternative that provides sensitive measurements of Trp in samples [9-13].

Recently, aptamers along with antibodies have been used to probe and selectively measure many biological and pharmaceutical compounds [14-18]. Aptamers have many advantages over antibodies. Namely, aptamers have high stability in the presence of different parameters such as pressure, temperature, $\mathrm{pH}$, in vitro synthesis, and labeling with different groups during synthesis [19]. It has been shown that some aptamers catalyze reactions similar to peroxidases [20-23]. For example, 
the guanine-rich aptamer that forms a G-quadruplex structure in the presence of hemin catalyzes the reduction of $\mathrm{H}_{2} \mathrm{O}_{2}$, which has been used in a wide range of applications [24].

When generating new electrochemical sensors, great attention has been paid to using various nanomaterials to immobilize the aptamer on the electrode surface, which subsequently alters the effective surface area, the electron transfer kinetics, and the sensitivity of the sensor [25-27]. Notably, magnetic nanoparticles have been favorably considered in many studies because of their high surface area, super paramagnetic properties, biocompatibility, and low toxicity [28-31]. However, magnetic nanoparticles have a strong tendency to oxidize and aggregate when exposed to air, which requires them to be coated with other materials. Covering the magnetic nanoparticles with a silica layer increases the stability of the nanoparticles and facilitates surface modification with different functional groups [32-35].

In this study, we first prepared the magnetic nanocomposite as an ionic liquid core-shell structure by sol-gel method in order to improve its conductivity and make it a suitable modifier for the preparation of electrochemical biosensors [31]. Next, dendritic gold nanostructures (DGNs) were electrochemically synthesized on the magnetic double-charged diazoniabicyclo [2.2.2] octane dichloride silica hybrid $\left(\mathrm{Fe}_{3} \mathrm{O}_{4} @ \mathrm{SiO}_{2} / \mathrm{DABCO}\right)$-modified screen-printed electrode (SPE) to not only increase the effective surface area and electrical conductivity, but also immobilize guanine-rich Trp aptamer. The presence of $\operatorname{Trp}$ allowed Trp aptamer to form hemin/G-quadruplex structure, enabling the efficient catalysis of the $\mathrm{H}_{2} \mathrm{O}_{2}$ reduction. Because of the dual amplification strategy based on DGNs/ $/ \mathrm{Fe}_{3} \mathrm{O}_{4} @ \mathrm{SiO}_{2} / \mathrm{DABCO}$ and Trp aptamer-hemin-mediated catalysis of $\mathrm{H}_{2} \mathrm{O}_{2}$ reduction, our sensor showed higher sensitivity than other electrochemical sensors for determining Trp levels. Notably, we discovered that the Trp aptamer-hemin has significantly improved the peroxidase-mimicking activity after binding to Trp, which is successfully utilized for the detection of Trp levels even in human serum.

\section{Materials and Methods}

\subsection{Reagents and Instruments}

Hexaammineruthenium (III) $\left(\left[\mathrm{Ru}\left(\mathrm{NH}_{3}\right)_{6}\right]^{3+}\right)$, 1,4-diazabicyclo[2.2.2]octane, $\mathrm{FeCl}_{3} \cdot 6 \mathrm{H}_{2} \mathrm{O}$, and $\mathrm{FeCl}_{2} \cdot 4 \mathrm{H}_{2} \mathrm{O}$, Tetraethyl orthosilicate, tryptophan, tyrosine, histidine, arginine, lysine, valine, and methionine were purchased from Sigma Aldrich (Seoul, Korea). All other chemicals were of analytical grade and supplied from Sigma Aldrich Company. Trp aptamer sequences (5'-SH- $\left(\mathrm{CH}_{2}\right)_{6}$-AGCAC GTTGGTTAGGTCAGGTTTGGGTTTCGTGC-3') were purchased from Bioneer Corp., Daejeon, Korea. The stock solution of Trp aptamer $(0.1 \mathrm{mM})$ was prepared in Tris-EDTA buffer solution $(5 \mathrm{mM}$ tris(2-carboxyethyl) phosphine (TCEP), $50 \mathrm{mM}$ Tris-HCl, $1.0 \mathrm{mM}$ EDTA, $\mathrm{pH}$ 8.0) and kept at room temperature for $1 \mathrm{~h}$ to reduce the disulfide bonds of Trp aptamer. The Trp aptamer was diluted in Tris- $\mathrm{HCl}$ buffer solution ( $50 \mathrm{mM}$ Tris- $\mathrm{HCl}$ and $10 \mathrm{mM} \mathrm{KCl}, \mathrm{pH}$ 7.2). All the electrochemical evaluations were performed at room temperature. The auto-lab PGSTAT 30 electrochemical analysis system was controlled using GPES 4.9 and FRA 4.9 software packages (EcoChemie, Utrecht, The Netherlands) was used for electrochemical measurements. Graphite screen-printed electrodes (SPEs) were purchased from Ecobioservices \& Researches (Florence, Italy). Electrochemical impedance spectroscopy (EIS) and cyclic voltammetry (CV) were recorded in $50 \mathrm{mM}$ Tris- $\mathrm{HCl}$ buffer solutions ( $\mathrm{pH}$ 7.4), containing $0.01 \mathrm{M}$ $\left[\mathrm{Fe}(\mathrm{CN})_{6}\right]^{3-/ 4-}$ and $100 \mathrm{mM} \mathrm{KCl}$, at a scan rate of $100 \mathrm{mV} / \mathrm{s}$ and the frequency ranged from $100 \mathrm{kHz}$ to $0.05 \mathrm{~Hz}$ at open circuit potential $(0.23 \mathrm{~V})$. Field emission scanning electron microscopy (FE-SEM) images of modified electrode surface at each step were recorded using Mira 3-XMU FE-SEM (TESCAN, Brno, Czech Republic).

\subsection{Synthesis of the $\mathrm{Fe}_{3} \mathrm{O}_{4} @ \mathrm{SiO}_{2} / \mathrm{DABCO}$}

The $\mathrm{Fe}_{3} \mathrm{O}_{4} @ \mathrm{SiO}_{2} / \mathrm{DABCO}$ nanocomposite was synthesized in three steps according to the method described by Bagheri et al. [36]. In the first step, magnetic nanoparticles (MNPs) were prepared by a co-precipitation method from the reaction of $\mathrm{FeCl}_{3} \cdot 6 \mathrm{H}_{2} \mathrm{O}$ and $\mathrm{FeCl}_{2} \cdot 4 \mathrm{H}_{2} \mathrm{O}$, which were then 
dried under vacuum at $60^{\circ} \mathrm{C}$. In the second step, bis(n-propyl trimethoxysilane)-1,4-diazoniabicycle [2.2.2] octane chloride (BPTDABCOCl) was prepared by the reaction of 1,4-diazabicycle [2.2.2] octane (DABCO) and 3-chloropropyl trimethoxysilane (CPTMS) in DMF and the resulting product was dried in an electrical oven. Finally, $\mathrm{Fe}_{3} \mathrm{O}_{4} @ \mathrm{SiO}_{2} / \mathrm{DABCO}$ nanocomposite was synthesized using MNPs, BPTDABCOCl, and tetraethyl orthosilicate (TEOS) by sol-gel method.

\subsection{Preparation of Trp Aptasensor}

Figure 1 shows a schematic of the different steps for constructing the Trp aptasensor. First, we synthesized $\mathrm{Fe}_{3} \mathrm{O}_{4} @ \mathrm{SiO}_{2} / \mathrm{DABCO}$ as a biocompatible nanocomposite to modify the electrode surface as described in Section 2.2. Next, the dendritic gold nanostructures (DGNs) were prepared through the electrodeposition of gold solution $\left(\mathrm{HAuCl}_{4} ; 0.5 \mathrm{mM}\right)$ on $\mathrm{Fe}_{3} \mathrm{O}_{4} @ \mathrm{SiO}_{2} / \mathrm{DABCO} / \mathrm{SPE}$ under the potential of $-0.23 \mathrm{~V}$ for a duration of $300 \mathrm{~s}$, and Trp aptamer $\left(3.0 \times 10^{-6} \mathrm{M}\right)$ was then immobilized on the electrode surface overnight at room temperature. Finally, the hemin solution $(20 \mu \mathrm{M})$ was dropped onto the electrode, which was incubated for $15 \mathrm{~min}$. The state was then ready for analysis of the samples containing Trp. After each step, the modified electrode was thoroughly washed using distilled water. The differential pulse voltammetry (DPV) was performed with the potential range from 0 to $-0.6 \mathrm{~V}$ in HEPES buffer (20 mM HEPES, pH 7.4, $100 \mathrm{mM} \mathrm{NaCl}$, and $50 \mathrm{mM} \mathrm{KCl}$ ), and $\mathrm{H}_{2} \mathrm{O}_{2}(20 \mu \mathrm{M})$. The error bars in all of the figures indicate the standard deviation among three replicates.

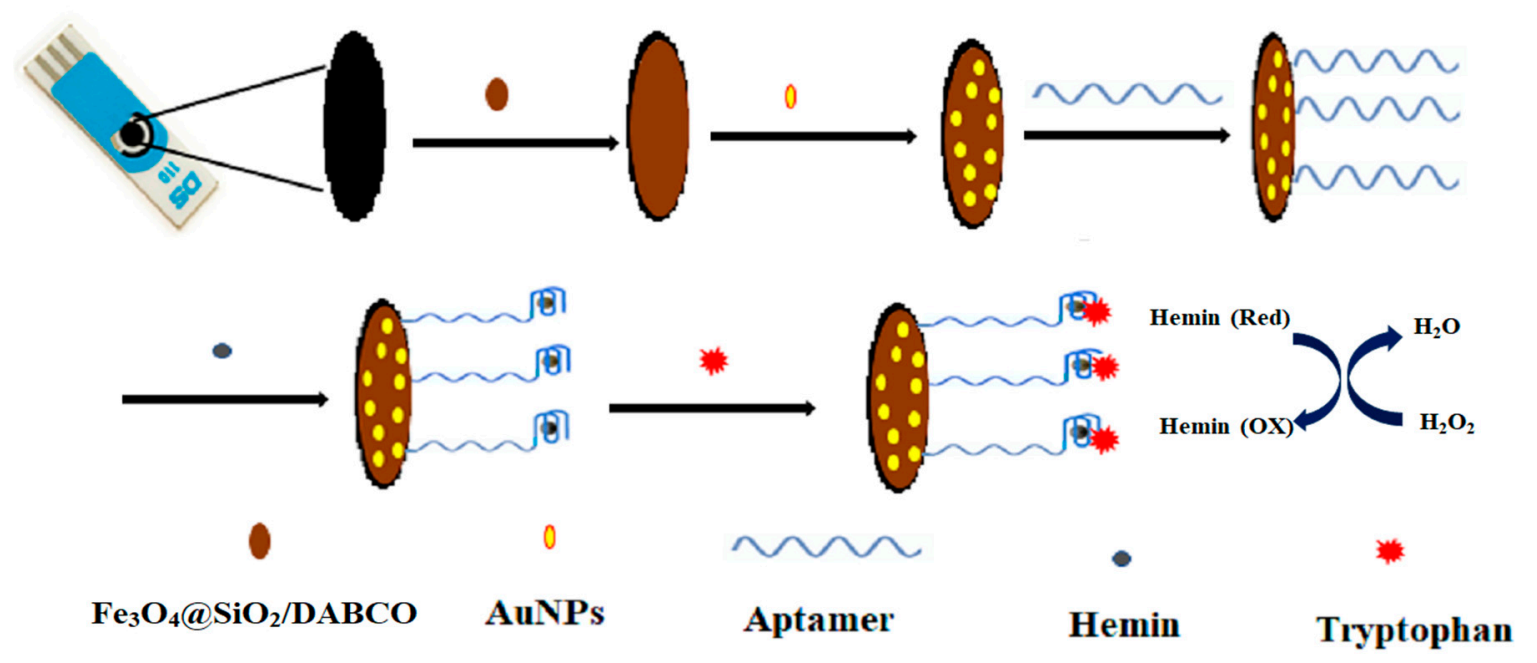

Figure 1. Schematic illustration for the construction of electrochemical Trp aptasensor.

\subsection{Determination of Trp in Human Serum}

To prevent protein adsorption on the electrode surface and the related interference with the measurement, the human serum was first de-proteinized using trichloroacetic acid and subjected to the centrifugation. After removing the precipitates, the supernatant was then diluted three-fold using 0.1 M PBS (pH 7.0) and different concentrations of Trp was spiked into diluted human serum. These samples were finally analyzed using the same procedures described in Section 2.3.

\section{Results}

\subsection{Characterization of Sensing Interface}

The surface morphologies of the bare SPE, $\mathrm{Fe}_{3} \mathrm{O}_{4} @ \mathrm{SiO}_{2} / \mathrm{DABCO} / \mathrm{SPE}$, and DGNs $/ \mathrm{Fe}_{3} \mathrm{O}_{4} @ \mathrm{SiO}_{2} /$ DABCO/SPE were first characterized using FE-SEM (Figure 2). As shown in Figure 2B, $\mathrm{Fe}_{3} \mathrm{O}_{4} @ \mathrm{SiO}_{2} /$ $\mathrm{DABCO} / \mathrm{SPE}$ displayed a uniform spherical structure with an average size of $23 \mathrm{~nm}$, which is different from the SPE (Figure 2A). In addition to the benefits of the ionic liquid framework, 
the presence of functional groups on magnetic nanocomposites leads to greater deposition of gold nanostructures and prevents the agglomeration of nanoparticles on the magnetic nanocomposite surface [36]. Furthermore, AuNPs with an average size of $13.5 \mathrm{~nm}$ were successfully deposited on the $\mathrm{Fe}_{3} \mathrm{O}_{4} @ \mathrm{SiO}_{2} / \mathrm{DABCO} / \mathrm{SPE}$ surface as demonstrated by a dendritic structure, which was achieved by the specific interaction with the functional groups of the magnetic nanocomposite (Figure $2 \mathrm{C}$ ). To prove that the dendritic structure is only formed with the help of magnetic nanocomposites, we obtained the SEM image of gold nanoparticles (AuNPs) electrodeposited on the surface of bare SPE without magnetic nanocomposites (Figure S1). We assumed that the deposition of AuNPs with a dendritic structure enabled the signal amplification as well as the immobilization of thiolated Trp aptamer on the electrode surface.
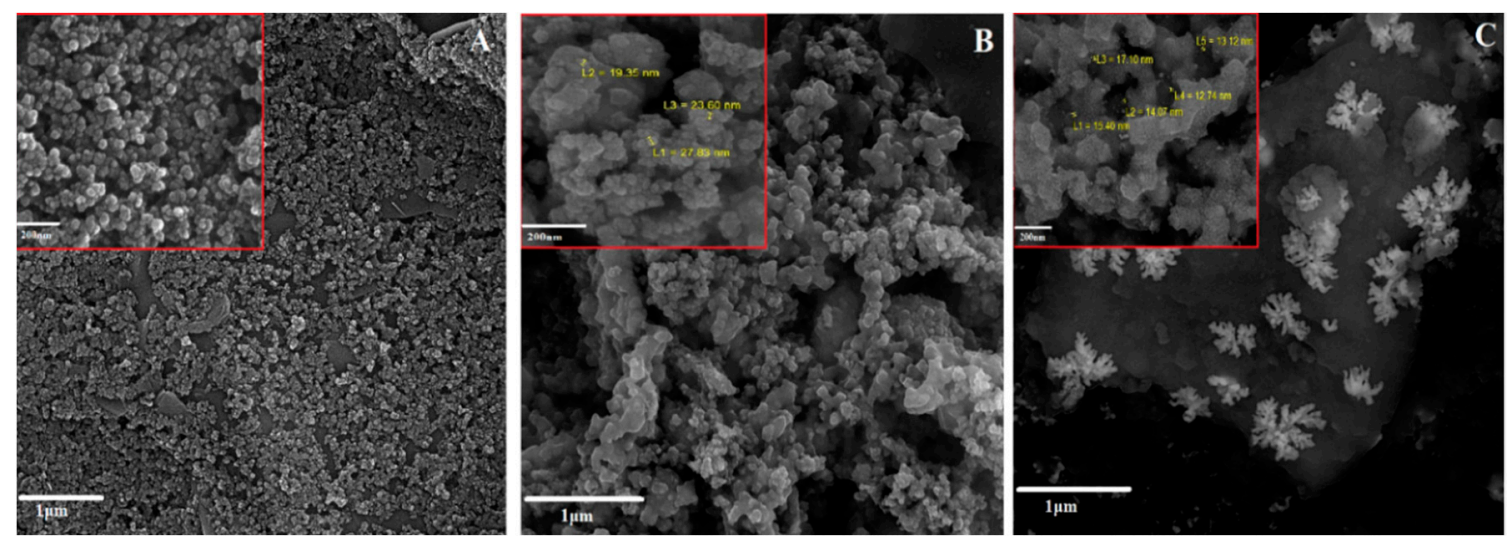

Figure 2. Characterization of sensing interface. FE-SEM images of (A) bare SPE, (B) $\mathrm{Fe}_{3} \mathrm{O}_{4} @ \mathrm{SiO}_{2} /$ $\mathrm{DABCO} / \mathrm{SPE}$, and (C) DGNs/ $\mathrm{Fe}_{3} \mathrm{O}_{4} @ \mathrm{SiO}_{2} / \mathrm{DABCO} / \mathrm{SPE}$. The measured particle size is indicated in yellow color. The scale bars in the high (inset) and low magnification are $200 \mathrm{~nm}$ and $1 \mu \mathrm{m}$, respectively.

Next, EIS and CV were recorded to investigate the fabrication process of the Trp aptasensor. Recently, there has been an escalating interest in using EIS for biological measurements since this technique can be performed within a narrow range of small potentials and have no detrimental effects on biological interactions [37]. Figure 3A shows Nyquist plots of different electrode surfaces in the presence of $\left[\mathrm{Fe}(\mathrm{CN})_{6}\right]^{3-/ 4-}$ redox couples. The bare SPE (a) exhibited a semicircle in the high frequency region with charge transfer resistance $\left(R_{c t}\right)$ of $1375 \Omega$, but the $R_{c t}$ decreased to $556 \Omega$ for $\mathrm{Fe}_{3} \mathrm{O}_{4} @ \mathrm{SiO}_{2} / \mathrm{DABCO} / \mathrm{SPE}(\mathrm{b})$, which indicates an improvement in the electron transfer ability of electrode surface. Furthermore, the deposition of AuNPs on the $\mathrm{Fe}_{3} \mathrm{O}_{4} @ \mathrm{SiO}_{2} / \mathrm{DABCO} / \mathrm{SPE}$ led to a significant decrease of $R_{c t}$ down to $190 \Omega$ (c). These data imply that DGNs have excellent electrochemical conductivity and facilitate the electron transfer between the modified electrode surface and the redox couple. However, after the immobilization of the Trp aptamer on the surface of DGNs/ $/ \mathrm{Fe}_{3} \mathrm{O}_{4} @ \mathrm{SiO}_{2} / \mathrm{DABCO} / \mathrm{SPE}$, the negative charge of the aptamer repelled the $\left[\mathrm{Fe}(\mathrm{CN})_{6}\right]^{3-/ 4-}$ redox couple, which resulted in increased $\mathrm{R}_{\mathrm{ct}}$ of $14,100 \Omega(\mathrm{d})$. Finally, the addition of $\operatorname{Trp}(0.9 \mathrm{nM})$ and hemin further increased $\mathrm{R}_{\mathrm{ct}}$ up to $38,455 \Omega(\mathrm{e})$, which indicated that the diffusion rate between the $\left[\mathrm{Fe}(\mathrm{CN})_{6}\right]^{3-/ 4-}$ redox couple and the electrode surface was reduced by non-effective electron transfer. These results confirmed the formation of the Trp-aptamer complex at the electrode surface. The EIS results were also supported using the CV measurements. As shown in Figure 3B, the changes in CVs of the $\left[\mathrm{Fe}(\mathrm{CN})_{6}\right]^{3-/ 4-}$ redox couple confirmed that each preparation step was successfully carried out on the electrodes surface, and the results are in good agreement with EIS experiments. 

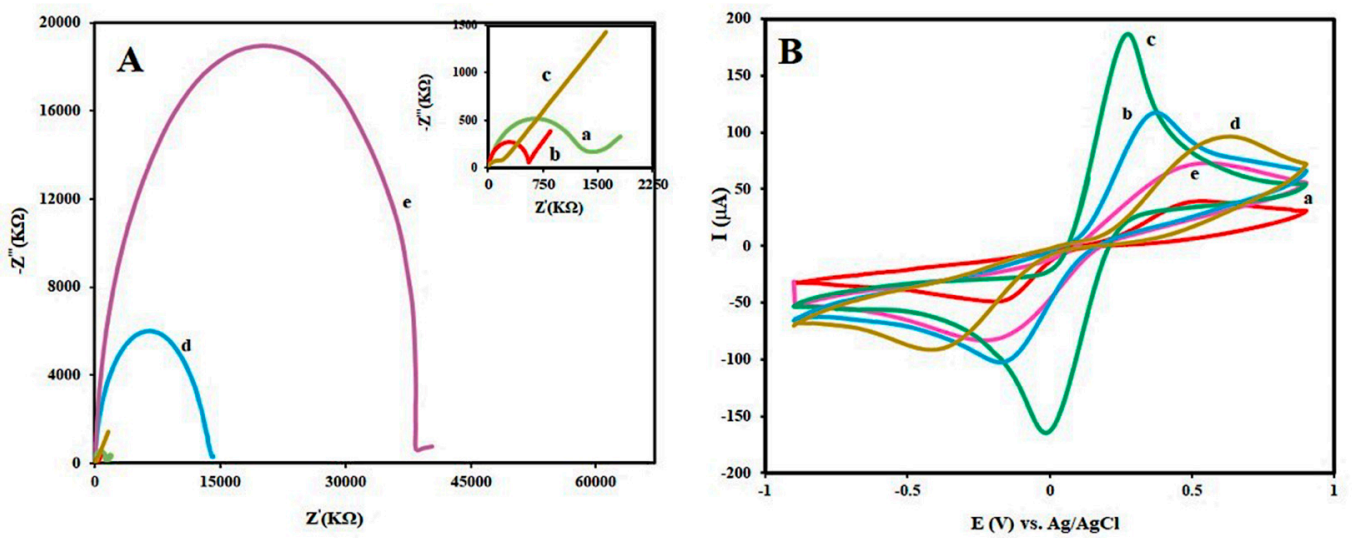

Figure 3. Characterization of different modification steps by (A) EIS and (B) $\mathrm{CV}$ in $0.01 \mathrm{M}\left[\mathrm{Fe}(\mathrm{CN})_{6}\right]^{3-}$ and $0.1 \mathrm{KCl}$ solution at a scan rate of $100 \mathrm{mV} \mathrm{s}^{-1}$ : bare $\mathrm{SPE}(\mathrm{a}), \mathrm{Fe}_{3} \mathrm{O}_{4} @ \mathrm{SiO}_{2} / \mathrm{DABCO} / \mathrm{SPE}$ (b), DGNs/ $/ \mathrm{Fe}_{3} \mathrm{O}_{4} @ \mathrm{SiO}_{2} / \mathrm{DABCO} / \mathrm{SPE}$ (c), Apt/DGNs/Fe $3 \mathrm{O}_{4} @ \mathrm{SiO}_{2} / \mathrm{DABCO} / \mathrm{SPE}$ (d), and Trp/hemin/Apt/ DGNs/ $/ \mathrm{Fe}_{3} \mathrm{O}_{4} @ \mathrm{SiO}_{2} / \mathrm{DABCO} / \mathrm{SPE}$ (e). The concentration of Trp was $0.9 \mathrm{nM}$.

\subsection{Aptamer Surface Density and Detection Feasibility of Trp Aptasensor}

The aptamer surface density on the modified electrode surface was investigated using the Tarlov equation (Equation (1)) [38]:

$$
\Gamma_{\text {apt }}=\Gamma_{o}(Z / M)\left(N_{A}\right)
$$

where $\Gamma_{\text {apt }}$ is the aptamer surface density (molecules $\left./ \mathrm{cm}^{2}\right), \Gamma_{0}$ is the quantity of adsorbed redox marker $\left[\mathrm{Ru}\left(\mathrm{NH}_{3}\right)_{6}\right]^{3+}, M$ is the number of aptamer bases, and $\mathrm{Z}$ is the charge of $\left[\mathrm{Ru}\left(\mathrm{NH}_{3}\right)_{6}\right]^{3+}$. After immobilizing the Trp aptamer on the modified electrode surface, chronocoulometric curves were recorded in the presence or absence of $200 \mu \mathrm{M}\left[\mathrm{Ru}\left(\mathrm{NH}_{3}\right)_{6}\right]^{3+}$ with $0.05 \mathrm{M} \mathrm{KCl}$ solution at a potential of $-0.3 \mathrm{~V}$. As shown in Figure $4 \mathrm{~A}$, the $\Gamma_{\text {apt }}$ was calculated to be $2.6 \times 10^{18}( \pm 1.2 \%)$ molecules $/ \mathrm{cm}^{2}$ using the Tarlov equation.
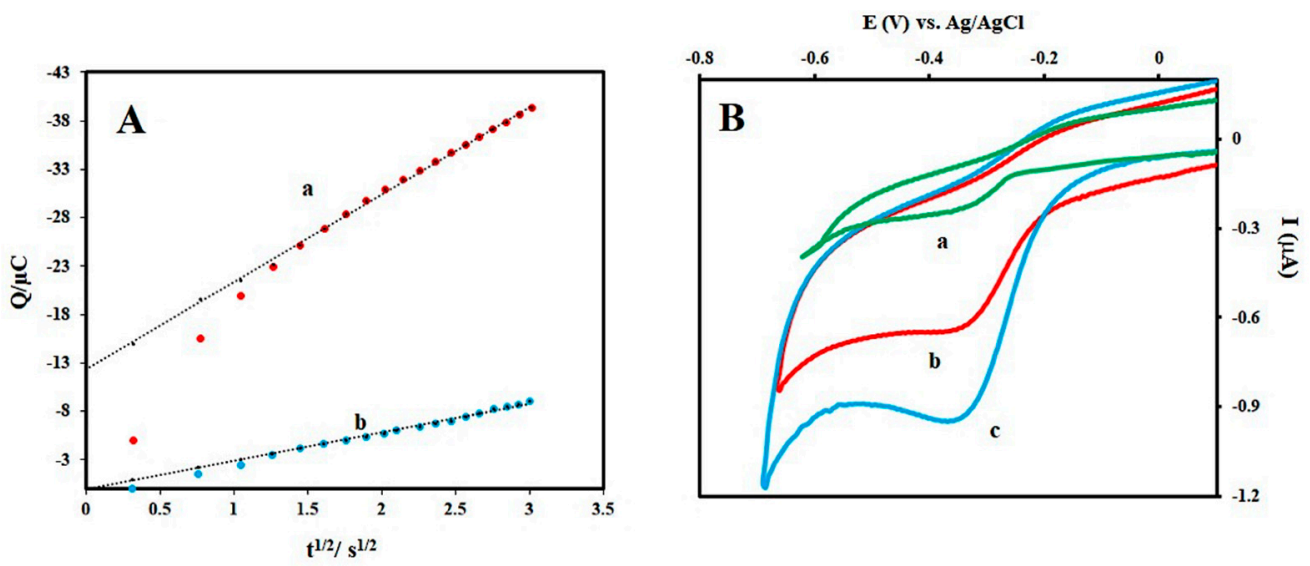

Figure 4. Aptamer surface density and detection feasibility of Trp aptasensor (A) Chronocoloumetric curves at Apt/DGNs/ $\mathrm{Fe}_{3} \mathrm{O}_{4} @ \mathrm{SiO}_{2} / \mathrm{DABCO} / \mathrm{SPE}$ in a solution of composed of $200 \mu \mathrm{M}\left[\mathrm{Ru}\left(\mathrm{NH}_{3}\right)_{6}\right]^{3+}$ and $0.05 \mathrm{M} \mathrm{KCl}$ (a), and containing $0.05 \mathrm{M} \mathrm{KCl}$ only (b). (B) CV signals of hemin/Apt/DGNs/Fe $\mathrm{O}_{4} @ \mathrm{SiO}_{2} /$ $\mathrm{DABCO} / \mathrm{SPE}$ in the absence of $\operatorname{Trp}(\mathrm{a})$, and in the presence of $3 \mathrm{nM} \operatorname{Trp}(\mathrm{b})$, and $100 \mathrm{nM} \operatorname{Trp}(\mathrm{c})$.

Next, to demonstrate the detection feasibility of Trp aptasensor, the CV method was used to measure reduction signals of $\mathrm{H}_{2} \mathrm{O}_{2}$ in the absence of Trp (a) and presence of $\operatorname{Trp}$ at $3 \mathrm{nM}$ (b) and $100 \mathrm{nM}$ (c) (Figure 4B). The Trp aptamer with hemin was not strong enough to form an active G-quadruplex structure for the effective catalysis of $\mathrm{H}_{2} \mathrm{O}_{2}$ reduction as indicated by the weak $\mathrm{H}_{2} \mathrm{O}_{2}$ current intensity (Figure 4B, a). On the other hand, the presence of Trp at $3 \mathrm{nM}$ (b) and $100 \mathrm{nM}$ (c) significantly 
increased the reduction signal of $\mathrm{H}_{2} \mathrm{O}_{2}$. These data confirm that the Trp aptamer forms a stable G-quadruplex structure only in the presence of Trp, and serves as an effective catalyst for the amplified electrochemical signal.

\subsection{Optimization of the Proposed Aptasensor}

To obtain the optimal condition for the proposed aptasensor, different concentrations of the aptamer $(1.0-6.0 \mu \mathrm{M})$ were applied onto the surface of the modified electrode and the EIS spectra were recorded. As the concentration of the aptamer increased up to $3 \mu \mathrm{M}$, the $\mathrm{R}_{\mathrm{ct}}$ increased, whereas the aptamer concentration beyond $4 \mu \mathrm{M}$ led to a decrease in the $\mathrm{R}_{\mathrm{ct}}$ (Figure S2A). At higher aptamer concentrations, the intermolecular hybridization of the complementary regions may lead to a decrease in the immobilization of the aptamer on the modified electrode surface. Additionally, we investigated the effect of Trp incubation time on the prepared sensor. EIS spectra results showed that the optimal time for trapping Trp molecules on the sensor surface is $40 \mathrm{~min}$ and incubating for longer did not have a significant effect (Figure S2B).

\subsection{Sensitivity of the Prepared Aptasensor}

As the Trp aptamer is rich in guanine, we assumed that in the presence of Trp, a stable G-quadruplex structure could form to effectively catalyze $\mathrm{H}_{2} \mathrm{O}_{2}$ reduction [39] (QGRS Mapper software, Table S1) [40,41]. By measuring the reduction signals of $\mathrm{H}_{2} \mathrm{O}_{2}$ using DPV technique, the performance of the designed sensor to detect different concentrations of Trp was evaluated. Figure 5A shows the DPV signals of $\mathrm{H}_{2} \mathrm{O}_{2}$ in the absence or presence of different concentrations of Trp. Figure 5B shows the calibration plots of $\mathrm{H}_{2} \mathrm{O}_{2}$ reduction signals versus Trp concentrations in three linear ranges. We observed that with increasing Trp concentrations, $\mathrm{H}_{2} \mathrm{O}_{2}$ reduction was more efficiently catalyzed because of the formation of stable G-quadruplex structure on the electrode surface. It is assumed that Trp induces the conformational change of aptamer, mediating the formation of stable G-quadruplex, and accordingly improves the peroxidase-like activity of hemin/G-quadruplex structure. As seen in the calibration plot (Figure 5B), the intensity of the current is proportional to the Trp concentration in the three ranges $(0.007-0.1 \mathrm{nM}, 0.1-10 \mathrm{nM}$, and 10-200 nM). The detection limit was estimated to be $0.002 \mathrm{nM}\left(\mathrm{LOD}=3 \mathrm{~S}_{\mathrm{b}} / \mathrm{m}\right.$, where $\mathrm{S}_{\mathrm{b}}$ is the standard deviation of the blank signal $(\mathrm{n}=7)$, and $\mathrm{m}$ is slope of the linear calibration range) [42,43], which is superior to that of other electrochemical detection methods (Table 1).
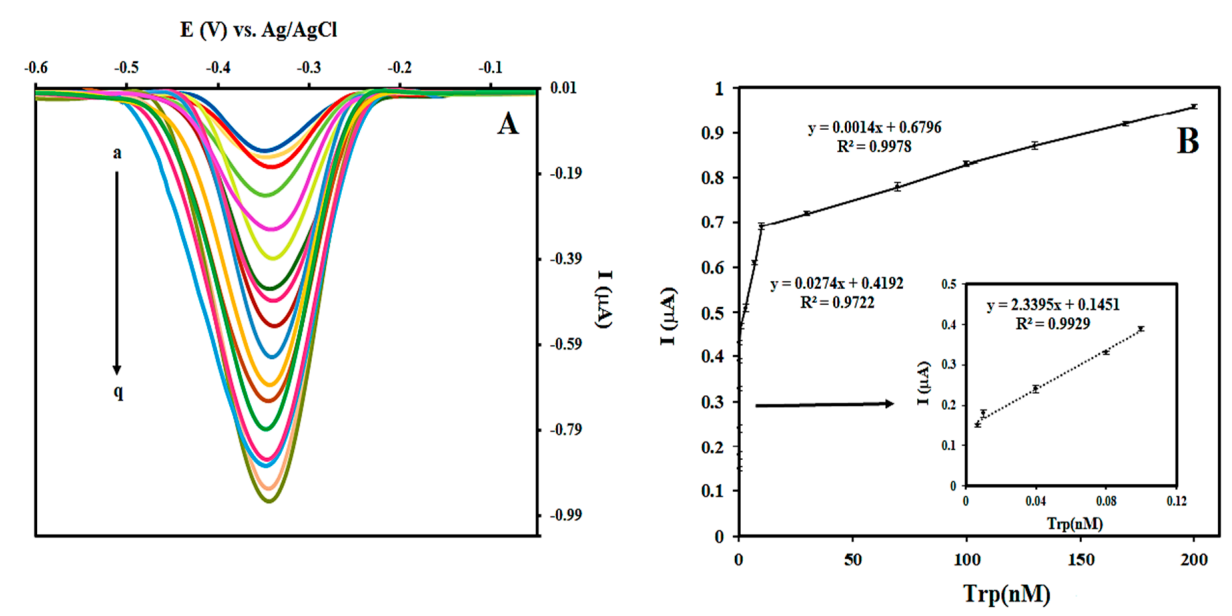

Figure 5. Sensitivity of the prepared aptasensor. (A) DPV signals of hemin/Apt/DGNs $/ \mathrm{Fe}_{3} \mathrm{O}_{4} @ \mathrm{SiO}_{2} /$ DABCO/SPE with different Trp concentrations: (a) 0, (b) 0.007, (c) 0.01, (d) 0.04, (e) 0.08, (f) 0.1, (g) 0.3, (h) 0.9, (i) 3, (j) 7, (k) 10, (l) 30, (m) 70, (n) 100, (o) 130, (p) 170, and (q) 200 nM. (B) The calibration plots of I vs. Trp concentration. 
Table 1. Comparison of the analytical performance between the proposed aptasensor and other detection methods for Trp.

\begin{tabular}{|c|c|c|c|c|}
\hline Sensing Surface & Electrochemical Method & Linear Range & Limit of Detection & Ref. \\
\hline GNP/CILE & SWV & $5 \times 10^{-3}-9 \times 10^{-1} \mathrm{M}$ & $4 \times 10^{-3} \mathrm{M}$ & [44] \\
\hline poly(p-ABSA) film/GCE & LSV & $1 \times 10^{-7}-10^{-5} \mathrm{M}$ & $7 \times 10^{-8} \mathrm{M}$ & [45] \\
\hline $\mathrm{SiO}_{2}$ nanoparticles/CPE & LSV & $1 \times 10^{-7}-5 \times 10^{-5} \mathrm{M}$ & $3.6 \times 10^{-8} \mathrm{M}$ & [46] \\
\hline $\begin{array}{l}\text { CuCoHCF/graphite } \\
\text { electrode }\end{array}$ & Amperometry & $1 \times 10^{-5}-9 \times 10^{-4} \mathrm{M}$ & $6 \times 10^{-6} \mathrm{M}$ & [47] \\
\hline SWNT/GCE & DPV & $4 \times 10^{-8}-1 \times 10^{-5} \mathrm{M}$ & $1 \times 10^{-8} \mathrm{M}$ & [48] \\
\hline PGE/GND & $\mathrm{CV}$ & $1 \times 10^{-8}-4 \times 10^{-6} \mathrm{M}$ & $3 \times 10^{-9} \mathrm{M}$ & [49] \\
\hline MWCNTs/SGE & DPV & $2 \times 10^{-7}-15 \times 10^{-6} \mathrm{M}$ & $14 \times 10^{-8} \mathrm{M}$ & [50] \\
\hline OPРy/CPE & ASV & $1 \times 10^{-2}-1 \times 10^{-1} \mathrm{M}$ & $1 \times 10^{-2} \mathrm{M}$ & [51] \\
\hline MIP-MWCNTs/GCE & $\mathrm{CV}$ & $2 \times 10^{-6}-1 \times 10^{-4} \mathrm{M}$ & $1 \times 10^{-9} \mathrm{M}$ & [9] \\
\hline PVP-GR/GCE & LSV & $6 \times 10^{-8}-1 \times 10^{-4} \mathrm{M}$ & $1 \times 10^{-8} \mathrm{M}$ & [11] \\
\hline $\mathrm{BiF} / \mathrm{BDDE}$ & DPV & $1 \times 10^{-7}-75 \times 10^{-6} \mathrm{M}$ & $3 \times 10^{-8} \mathrm{M}$ & [52] \\
\hline AuNPs/FSN/SPE & DPV & $0.06-250 \times 10^{-9} \mathrm{M}$ & $1 \times 10^{-11} \mathrm{M}$ & [12] \\
\hline $\mathrm{DGNs} / \mathrm{Fe}_{3} \mathrm{O}_{4} @ \mathrm{SiO}_{2}-\mathrm{DABCO} / \mathrm{SPE}$ & DPV & $\begin{array}{c}0.007-0.1,0.1-10 \\
\text { and } 10-200 \times 10^{-9} \mathrm{M}\end{array}$ & $2 \times 10^{-12} \mathrm{M}$ & $\begin{array}{l}\text { This } \\
\text { study }\end{array}$ \\
\hline
\end{tabular}

Carbon ionic liquid electrode (CILE) modified with gold nanoparticle (GNP), poly(p-aminobenzene sulfonic acid) [Poly(p-ABSA)] modified glassy carbon electrode (GCE), carbon paste electrode (CPE), mixed metal (copper and cobalt) hexacyanoferrate (CuCoHCF), single-wall carbon nanotubes (SWNT), pyrolytic graphite electrode (PGE) modified with graphite/nanodiamond film (GND), multi-walled carbon nanotubes modified sol-gel electrode (MWCNTs/SGE), overoxidized polypyrrole film modified carbon paste electrode (OPPy/CPE), molecularly imprinted polymers (MIP), Polyvinylpyrrolidone functionalized graphene (PVP-GR), boron-doped diamond electrode modified in situ with bismuth film (BiF/ BDDE).

\subsection{Selectivity, Real Sample, Reproducibility, and Stability}

Finally, the selectivity of this sensor was examined by measuring the reduction signals of $\mathrm{H}_{2} \mathrm{O}_{2}$ using DPV technique in the presence of $7 \mathrm{nM}$ of Trp (a), and $20 \mathrm{nM}$ of either tyrosine (b), histidine (c), arginine (d), lysine (e), valine (f), or methionine (g), and a blank control (h) (Figure 6). The $\mathrm{H}_{2} \mathrm{O}_{2}$ reduction signal in the presence of Trp was higher than other amino acids that showed negligible responses comparable to the blank control. To demonstrate the potential clinical application for this sensor, three concentrations of Trp were spiked in diluted human blood serum (33\%), which were analyzed using our proposed method. The results in Table S2 showed that the prepared aptasensor analyzes Trp in the human blood serum samples with excellent reproducibility and precision as evidenced by the coefficient of variation $(<2 \%)$ and accuracy $(<10 \%)$. Regarding the reproducibility between samples, we prepared the five different aptasensors and measured the signal in the presence of $\operatorname{Trp}(7 \mathrm{nM})$. The new results show that the relative standard deviation is $2.8 \%$, indicating that the fabricated sensor has an excellent reproducibility. Furthermore, the prepared aptasensors were stored at $4{ }^{\circ} \mathrm{C}$ in wet chamber for 3 weeks to investigate the stability of the developed aptasensor. As shown in Figure S3, 94\% of the initial electrochemical signal in the presence of $\operatorname{Trp}(7 \mathrm{nM})$ was maintained at 21 days after the preparation of sensors, proving the high stability of the prepared aptasensor. 


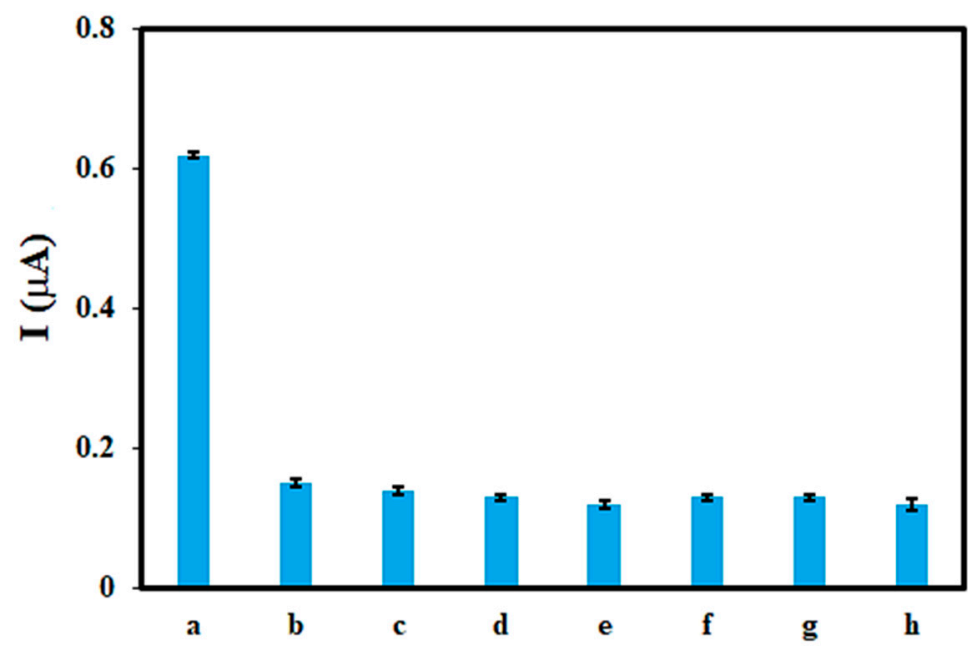

Figure 6. DPV responses in the presence of different amino acids (a) Trp and (b) tyrosine, (c) histidine, (d) arginine, (e) lysine, (f) valine, (g) methionine, and (h) blank. The concentration of Trp was $7 \mathrm{nM}$ and other amino acids were $20 \mathrm{nM}$.

\section{Conclusions}

We have developed a sensitive and selective electrochemical aptasensor for the detection of Trp using a hemin/G-quadruplex structure to amplify the $\mathrm{H}_{2} \mathrm{O}_{2}$ reduction signal. The fabricated aptasensor showed a low detection limit, wide linear range, and excellent reproducibility to measure Trp levels. The high sensitivity and reliable performance of this aptasensor are attributed to the dual approach for signal amplification. First, the modified electrode with DGNs/ $/ \mathrm{Fe}_{3} \mathrm{O}_{4} @ \mathrm{SiO}_{2} / \mathrm{DABCO} / \mathrm{SPE}$ led to an increase in the effective surface area, electron transfer, and electrochemical signal. Second, the hemin/G- quadruplex structure served as a catalyst to enhance the $\mathrm{H}_{2} \mathrm{O}_{2}$ reduction signal. Furthermore, the prepared aptasensor exhibited high selectivity toward Trp and detected Trp in human blood serum with high levels of accuracy, which suggests the potential application of this sensor for clinical use.

Supplementary Materials: The following are available online at http://www.mdpi.com/2227-9040/8/4/100/s1, Figure S1: FE-SEM images of AuNPs/SPE, Figure S2: Optimization of the prepared aptasensor (Apt/DGNs/Fe $3 \mathrm{O}_{4}$ $@ \mathrm{SiO}_{2} / \mathrm{DABCO} / \mathrm{SPE}$ ). (A) Optimization of aptamer concentration for preparation of aptasensor: $1 \mu \mathrm{M}(\mathrm{a}), 2 \mu \mathrm{M}(\mathrm{b})$, $3 \mu \mathrm{M}(\mathrm{c}), 4 \mu \mathrm{M}(\mathrm{d}), 5 \mu \mathrm{M}(\mathrm{e})$, and $6 \mu \mathrm{M}$ (f). (B) Optimization of incubation time for the interaction of aptamer $(3 \mu \mathrm{M})$ with $\operatorname{Trp}(0.9 \mathrm{nM})$, Figure S3: Stability of the prepared aptasensor, Table S1: Analysis of Trp aptamer sequence by QGRS Mapper software, Table S2: Analysis of human serum samples with Trp at different concentrations.

Author Contributions: Carrying out experimental work, discussion of the results, and writing the text A.B.H.; editing of the text and supervision J.B.R. and K.S.P. All authors have read and agreed to the published version of the manuscript.

Funding: This work was supported by Konkuk University in 2019.

Conflicts of Interest: The authors declare no conflict of interest.

\section{References}

1. Friedman, M. Analysis, Nutrition, and Health Benefits of Tryptophan. Int. J. Tryptophan Res. $2018,11$. [CrossRef] [PubMed]

2. Palego, L.; Betti, L.; Rossi, A.; Giannaccini, G. Tryptophan Biochemistry: Structural, Nutritional, Metabolic, and Medical Aspects in Humans. J. Amino Acids 2016, 2016, 1-13. [CrossRef] [PubMed]

3. Xu, D.; Sánchez-López, E.; Wang, Q.; Jiang, Z.; Marina, M.L. Determination of L-Norvaline and L-Tryptophan in Dietary Supplements by Nano-LC Using an O-[2-(Methacryloyloxy)-Ethylcarbamoyl]10,11-Dihydroquinidine-Silica Hybrid Monolithic Column. J. Pharm. Anal. 2019, 10, 70-77. [CrossRef] 
4. Delgado-Andrade, C.; Rufián-Henares, J.; Jiménez, S.; Morales, F.J. Tryptophan determination in milk-based ingredients and dried sport supplements by liquid chromatography with fluorescence detection. Food Chem. 2006, 98, 580-585. [CrossRef]

5. Ren, J.; Zhao, M.; Wang, J.; Cui, C.; Yang, B. Spectrophotometric Method for Determination of Tryptophan in Protein Hydrolysates. J. Food Tech. Biotech. 2007, 45, 360-366.

6. Lin, Z.; Chen, X.; Cai, Z.; Li, P.; Chen, X.; Wang, X. Chemiluminescence of Tryptophan and Histidine in $\mathrm{Ru}(\mathrm{Bpy})_{3}{ }^{2+}-\mathrm{KMnO} 4$ Aqueous Solution. Talanta 2008, 75, 544-550. [CrossRef] [PubMed]

7. Eser, B.; Özkan, Y.; Dinçel, A.S. Determination of Tryptophan and Kynurenine by LC-MS/MS by Using Amlodipine as an Internal Standard. J. Am. Soc. Mass Spectrom. 2020, 31, 379-385. [CrossRef]

8. Hazra, C.; Samanta, T.; Mahalingam, V. A resonance energy transfer approach for the selective detection of aromatic amino acids. J. Mater. Chem. C 2014, 2, 10157-10163. [CrossRef]

9. Wu, Y.; Deng, P.; Tian, Y.; Ding, Z.; Li, G.; Liu, J.; Zuberi, Z.; He, Q. Rapid recognition and determination of tryptophan by carbon nanotubes and molecularly imprinted polymer-modified glassy carbon electrode. Bioelectrochemistry 2020, 131, 107393. [CrossRef]

10. Idili, A.; Gerson, J.; Parolo, C.; Kippin, T.; Plaxco, K.W. An electrochemical aptamer-based sensor for the rapid and convenient measurement of l-tryptophan. Anal. Bioanal. Chem. 2019, 411, 4629-4635. [CrossRef]

11. He, Q.; Liu, J.; Feng, J.; Wu, Y.; Tian, Y.; Li, G.; Chen, D. Sensitive Voltammetric Sensor for Tryptophan Detection by Using Polyvinylpyrrolidone Functionalized Graphene/GCE. Nanomaterials 2020, 10, 125. [CrossRef] [PubMed]

12. Hashkavayi, A.B.; Raoof, J.-B.; Ojani, R. Construction of a highly sensitive signal-on aptasensor based on gold nanoparticles/functionalized silica nanoparticles for selective detection of tryptophan. Anal. Bioanal. Chem. 2017, 409, 6429-6438. [CrossRef]

13. Hashkavayi, A.B.; Raoof, J.-B. Ultrasensitive and reusable electrochemical aptasensor for detection of tryptophan using of $\left[\mathrm{Fe}(\mathrm{bpy})_{3}\right]\left(\mathrm{p}_{-}-\mathrm{CH}_{3} \mathrm{C}_{6} \mathrm{H}_{4} \mathrm{SO}_{2}\right)_{2}$ as an electroactive indicator. J. Pharm. Biomed. Anal. 2019, 163, 180-187. [CrossRef] [PubMed]

14. Hashkavayi, A.B.; Raoof, J.-B.; Ojani, R.; Asl, E.H. Label-Free Electrochemical Aptasensor for Determination of Chloramphenicol Based on Gold Nanocubes-Modified Screen-Printed Gold Electrode. Electroanalysis 2015, 27, 1449-1456. [CrossRef]

15. Hashkavayi, A.B.; Raoof, J.B.; Azimi, R.; Ojani, R. Label-free and sensitive aptasensor based on dendritic gold nanostructures on functionalized SBA-15 for determination of chloramphenicol. Anal. Bioanal. Chem. 2016, 408, 2557-2565. [CrossRef]

16. Hashkavayi, A.B.; Raoof, J.-B.; Ojani, R.; Kavoosian, S. Ultrasensitive electrochemical aptasensor based on sandwich architecture for selective label-free detection of colorectal cancer (CT26) cells. Biosens. Bioelectron. 2017, 92, 630-637. [CrossRef]

17. Park, K.S. Nucleic acid aptamer-based methods for diagnosis of infections. Biosens. Bioelectron. 2018, 102, 179-188. [CrossRef]

18. Park, K.S.; Lee, C.Y.; Kang, K.S.; Park, H.G. Aptamer-mediated universal enzyme assay based on target-triggered DNA polymerase activity. Biosens. Bioelectron. 2017, 88, 48-54. [CrossRef]

19. Hashkavayi, A.B.; Raoof, J.-B.; Ojani, R. Preparation of Epirubicin Aptasensor Using Curcumin as Hybridization Indicator: Competitive Binding Assay between Complementary Strand of Aptamer and Epirubicin. Electroanalysis 2018, 30, 378-385. [CrossRef]

20. Yu, X.; Lin, Y.; Wang, X.; Xu, L.; Wang, Z.; Fu, F. Exonuclease-assisted multicolor aptasensor for visual detection of ochratoxin A based on G-quadruplex-hemin DNAzyme-mediated etching of gold nanorod. J. Microchim. Acta 2018, 185, 259. [CrossRef]

21. Golub, E.; Albada, H.B.; Liao, W.-C.; Biniuri, Y.; Willner, I.; Albada, B. Nucleoapzymes: Hemin/G-Quadruplex DNAzyme-Aptamer Binding Site Conjugates with Superior Enzyme-like Catalytic Functions. J. Am. Chem. Soc. 2016, 138. [CrossRef] [PubMed]

22. Shi, L.; Yu, Y.; Chen, Z.; Zhang, L.; He, S.; Shi, Q.; Yang, H. A label-free hemin/G-quadruplex DNAzyme biosensor developed on electrochemically modified electrodes for detection of a HBV DNA segment. RSC Adv. 2015, 5, 11541-11548. [CrossRef]

23. Wu, S.-H.; Tang, Y.; Chen, L.; Ma, X.-G.; Tian, S.-M.; Sun, J.-J. Amplified electrochemical hydrogen peroxide reduction based on hemin/G-quadruplex DNAzyme as electrocatalyst at gold particles modified heated copper disk electrode. Biosens. Bioelectron. 2015, 73, 41-46. [CrossRef] [PubMed] 
24. Shen, B.; Wang, Q.; Zhu, D.; Luo, J.; Cheng, G.; He, P.; Fang, Y. G-Quadruplex-Based DNAzymes Aptasensor for the Amplified Electrochemical Detection of Thrombin. Electroanalysis 2010, 22, 2985-2990. [CrossRef]

25. Hashkavayi, A.B.; Hashemnia, S.; Osfouri, S.; Zarei, S. Electrochemical Study of Antioxidant Capacity of Gracilaria Pygmaea Macro-Algae Based on the Green Synthesis of Gold Nanoparticles: Assessment of Its Cytotoxic Effect on Four Cancer Cell Lines. J. Electrochem. Soc. 2019, 166, B969-B977. [CrossRef]

26. Raoof, J.-B.; Bagheryan, Z.; Hashkavayi, A.B. Development of a DNA biosensor based on MCM41 modified screen-printed graphite electrode for the study of the short sequence of the p53 tumor suppressor gene in hybridization and its interaction with the flutamide drug using hemin as the electrochemical label. New J. Chem. 2020, 44, 2016-2021.

27. Rahimi-Mohseni, M.; Raoof, J.B.; Ojani, R.; Aghajanzadeh, T.A.; Hashkavayi, A.B. Development of a new paper based nano-biosensor using the co-catalytic effect of tyrosinase from banana peel tissue (Musa Cavendish) and functionalized silica nanoparticles for voltammetric determination of l-tyrosine. Int. J. Biol. Macromol. 2018, 113, 648-654. [CrossRef]

28. Li, F.; Huang, Y.; Huang, K.; Lin, J.; Huang, P. Functional Magnetic Graphene Composites for Biosensing. Int. J. Mol. Sci. 2020, 21, 390. [CrossRef]

29. Doaga, R.; McCormac, T.; Dempsey, E. Functionalized magnetic nanomaterials for electrochemical biosensing of cholesterol and cholesteryl palmitate. J. Microchim. Acta 2020, 187, 1-10. [CrossRef]

30. Rajeev, G.; Cowin, A.J.; Voelcker, N.H.; Simon, B.P. Magnetic Nanoparticles Enhance Pore Blockage-Based Electrochemical Detection of a Wound Biomarker. Front. Chem. 2019, 7, 438. [CrossRef]

31. Cho, I.-H.; Kim, D.H.; Park, S. Electrochemical biosensors: Perspective on functional nanomaterials for on-site analysis. J. Biomater. Res. 2020, 24, 1-12. [CrossRef]

32. Silva, S.M.; Tavallaie, R.; Sandiford, L.; Tilley, R.D.; Gooding, J.J. Gold Coated Magnetic Nanoparticles: From Preparation to Surface Modification for Analytical and Biomedical Applications. Chemcomm 2016, 47, 7528-7540.

33. Phama, X.-H.; Hahm, E.; Kim,H.-M.; Son, B.S.; Jo, A.; An, J.; Thi, T.A.T.; Nguyen, D.Q.; Jun, B.-H. Silica-Coated Magnetic Iron Oxide Nanoparticles Grafted onto Graphene Oxide for Protein Isolation. Nanomaterials 2020, 10, 117. [CrossRef] [PubMed]

34. Glaria, A.; Soulé, S.; Hallali, N.; Ojo, W.-S.; Mirjolet, M.; Fuks, G.; Cornejo, A.; Allouche, J.; Dupin, J.C.; Martinez, H.; et al. Silica coated iron nanoparticles: Synthesis, interface control, magnetic and hyperthermia properties. RSC Adv. 2018, 8, 32146-32156. [CrossRef]

35. Sharafi, Z.; Bakhshi, B.; Javidi, J.; Adrangi, S. Synthesis of Silica-coated Iron Oxide Nanoparticles: Preventing Aggregation without Using Additives or Seed Pretreatment. Iran. J. Pharm. Res. IJPR 2018, 17, 386-395.

36. Hashkavayi, A.B.; Raoof, J.B. Design an Aptasensor Based on Structure-Switching Aptamer on Dendritic Gold Nanostructures/Fe $\mathrm{F}_{4} @ \mathrm{SiO}_{2} /$ DabCO Modified Screen Printed Electrode for Highly Selective Detection of Epirubicin. Biosens. Bioelectron. 2017, 91, 650-657. [CrossRef]

37. Pajkossy, T. Voltammetry Coupled with Impedance Spectroscopy. J. Solid State Electrochem. 2020, 24, 2157-2159. [CrossRef]

38. Steel, A.B.; Herne, T.M.; Tarlov, M.J. Electrochemical Quantitation of DNA Immobilized on Gold. J. Anal. Chem. 1998, 70, 4670-4677. [CrossRef]

39. Yang, X.; Han, Q.; Zhang, Y.; Wu, J.; Tang, X.; Dong, C.; Liu, W. Determination of free tryptophan in serum with aptamer-Comparison of two aptasensors. Talanta 2015, 131, 672-677. [CrossRef]

40. Huang, H.; Zhang, J.; Harvey, S.E.; Hu, X.; Cheng, C. RNA G-quadruplex secondary structure promotes alternative splicing via the RNA-binding protein hnRNPF. Genes Dev. Chang. 2017, 31, 2296-2309. [CrossRef]

41. Kikin, O.; D'Antonio, L.; Bagga, P.S. QGRS Mapper: A web-based server for predicting G-quadruplexes in nucleotide sequences. Nucleic Acids Res. 2006, 34, W676-W682. [CrossRef] [PubMed]

42. Martínez-García, G.; Julián, E.P.; Agüí, L.; Cabré, N.; Joven, J.; Yáñez-Sedeño, P.; Pingarrón, J.M. An Electrochemical Enzyme Biosensor for 3-Hydroxybutyrate Detection Using Screen-Printed Electrodes Modified by Reduced Graphene Oxide and Thionine. Biosensors 2017, 7, 50. [CrossRef]

43. Dermiş, S.; Cay, H.Y. Electrochemical behaviour of sertraline hydrochloride at a glassy carbon electrode and its determination in pharmaceutical products using osteryoung square wave voltammetry. Pharmazie 2010, 65, 182-187. [PubMed]

44. Safavi, A.; Momeni, S. Electrocatalytic Oxidation of Tryptophan at Gold Nanoparticle-Modified Carbon Ionic Liquid Electrode. Electroanalysis 2010, 22, 2848-2855. [CrossRef] 
45. Yu, Y.; Luo, D.; Zhan, G.; Li, C. Electrochemical Investigation of Tryptophan at a Poly (P-Aminobenzene Sulfonic Acid) Film Modified Glassy Carbon Electrode. J. Bull. Korean Chem. Soc. 2008, 29, 928.

46. Xu, M.; Ma, M.; Ma, Y. Electrochemical determination of tryptophan based on silicon dioxide nanopartilces modified carbon paste electrode. Russ. J. Electrochem. 2012, 48, 489-494. [CrossRef]

47. Liu, Y.; Xu, L. Electrochemical Sensor for Tryptophan Determination Based on Copper-cobalt Hexacyanoferrate Film Modified Graphite Electrode. Sensors 2007, 7, 2446-2457. [CrossRef]

48. Huang, W.; Mai, G.; Liu, Y.; Yang, C.; Qua, W. Voltammetric Determination of Tryptophan at a Single-Wall Carbon Nanotubes Modified Electrode. J. Nanosci. Nanotechnol. 2004, 4, 423-427. [CrossRef] [PubMed]

49. Shahrokhian, S.; Bayat, M. Voltammetric Determination of Tryptophan and 5-Hydroxytryptophan Using Graphite Electrode Modified with a Thin Film of Graphite/Diamond Nano-Mixture and Determination of Omeprazole Using Graphite Electrode; Department of Chemistry, Sharif University of Technology: Tehran, Iran, 2010.

50. Majidi, M.R.; Salimi, A.; Alipour, E. Development of Voltammetric Sensor for Determination of Tryptophan Using MWCNTs-Modified Sol-Gel Electrode. J. Chin. Chem. Soc. 2013, 60, 1473-1478. [CrossRef]

51. Chen, Z.-D.; Okamura, K.; Hanaki, M.; Nagaoka, T. Selective Determination of Tryptophan by Using a Carbon Paste Electrode Modified with an Overoxidized Polypyrrole Film. Anal. Sci. 2002, 18, 417-421. [CrossRef]

52. Sadok, I.; Tyszczuk-Rotko, K.; Mroczka, R.; Staniszewska, M. Simultaneous voltammetric analysis of tryptophan and kynurenine in culture medium from human cancer cells. Talanta 2020, 209, 120574. [CrossRef]

Publisher's Note: MDPI stays neutral with regard to jurisdictional claims in published maps and institutional affiliations.

(C) 2020 by the authors. Licensee MDPI, Basel, Switzerland. This article is an open access article distributed under the terms and conditions of the Creative Commons Attribution (CC BY) license (http://creativecommons.org/licenses/by/4.0/). 